\title{
Production of Doubly Charged Ions Using a Hollow Cathode Ion Source with an Evaporator
}

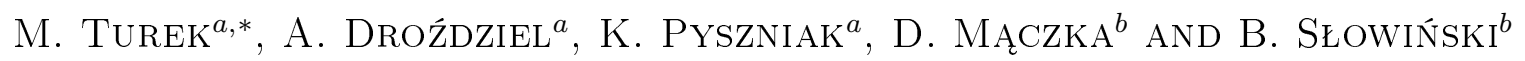 \\ ${ }^{a}$ Institute of Physics, Maria Curie-Skłodowska University, pl. M. Curie-Skłodowskiej 1, 20-031 Lublin, Poland \\ ${ }^{b}$ National Centre for Nuclear Studies, Otwock-Świerk, Poland
}

\begin{abstract}
The paper describes the production of doubly charged ions from solids and gases using a hollow cathode ion source with an internal evaporator heated by a spiral cathode filament and arc discharge. The obtained currents were $15 \mu \mathrm{A}$ for $\mathrm{Bi}^{2+}, 10 \mu \mathrm{A}$ for $\mathrm{As}^{2+}$ and $\mathrm{Al}^{2+}, 8 \mu \mathrm{A}$ for $\mathrm{Kr}^{2+}$ and $\mathrm{Xe}^{2+}, 5 \mu \mathrm{A}$ for $\mathrm{In}^{2+}$ and $\mathrm{Ge}^{2+}$, enabling moderate dose implantations $\left(\approx 10^{15} \mathrm{~cm}^{-3}\right.$ ) with doubly charged ions. Characteristics of the ion source are presented and discussed in order to choose the optimal working parameters. A brief presentation of numerical model of doubly and singly charged ions in the ion source is given. The calculated results (dependences of ion current on the anode voltage) are in good agreement with the experimental data.
\end{abstract}

DOI: $10.12693 /$ APhysPolA.123.843

PACS: 07.77.Ka, 34.80.Dp, 61.72.uj

\section{Introduction}

Multiply charged ions are widely used in different fields of research. Irradiation of solid surfaces with the ions carrying high charge enables achieving large values of sputtering coefficient [1]. The bombardment with highly charged ions leads also to formation of nanostructures [2] e.g. nanohillocks [3]. Multiply charged ions are used for modification of properties of metals [4] and polymers [5]. Making use of doubly charged ions (or ions in even higher charge states) is the simplest way to increase implantation depth without any changes in the construction of the implanter, as the kinetic energy of the ion having the charge $n_{\mathrm{e}}$ is $n$ times larger than the energy of the singly charged ion accelerated by the same voltage.

There are several methods of effective production of ions in higher charge states. The most popular approach is based on the electron cyclotron resonance [6,7]. Other solutions make use of electron [8] or laser $[9,10]$ beams for multiple ionization. Doubly charged ions are also efficiently produced in arc discharge [11] and liquid metal ion sources $[12,13]$.

In the paper we describe the production of beams of doubly charged ions of gaseous, metallic and non-metallic elements using an arc discharge ion source with a hollow cathode and the internal evaporator [14, 15]. The ion source is a next step in development of a Nielsen [16] type based arc discharge ion source with a cylindrical anode $[17,18]$ which became a basic ion source in the Institute of Physics in Lublin, offering possibility of implantations with a variety of ions, including ions of rare earths. It is worth mentioning that the improved version of the ion source was able to produce ion currents approximately twice as high as the basic version. This was

*corresponding author; e-mail: mturek@kft.umcs.lublin.pl mainly due to the proximity of the arc discharge region and the extraction opening.

The paper contains a brief description of the ion source and the experimental setup. The basic characteristics of the ion source are presented for doubly charged ions, in a manner similar to that of the cylindrical anode ion source [19], including the dependences of ion current and the discharge voltage on the cathode and the discharge currents as well as on the strength of the magnetic field the ionization chamber is immersed in. The measurements were done in order to find the optimal values of operational parameters, resulting in as high as possible doubly charged ion currents. The numerical model of doubly charged ions is also presented and discussed. Some of the results provided by the model are compared to the experimental data - good agreement has been achieved.

\section{Construction of the ion source}

Detailed description of the hollow cathode ion source with an evaporator could be found in [14] and its schematic view is shown in Fig. 1. A hollow cathode chamber consists of two cylindrical parts made of molybdenum, separated by a boron nitride insulator. A spiral cathode filament is fixed between the chamber cylinders and is made of tungsten wire of a $0.75 \mathrm{~mm}$ diameter. The typical values of the cathode current $I_{\mathrm{c}}$ are in the range 25-35 A, usually higher than in the case of a cylindrical anode source due to the fact that the evaporator is heated mainly by a hot filament. The average lifetime of the cathode depends on the cathode and discharge currents and reaches $50 \mathrm{~h}$.

The arc discharge region is between the front part of the hollow cathode chamber and the funnel-shaped anode. Both these facts (the proximity of the discharge region and extraction opening and the shape of the anode) result in a high performance of the ion source. Soon 


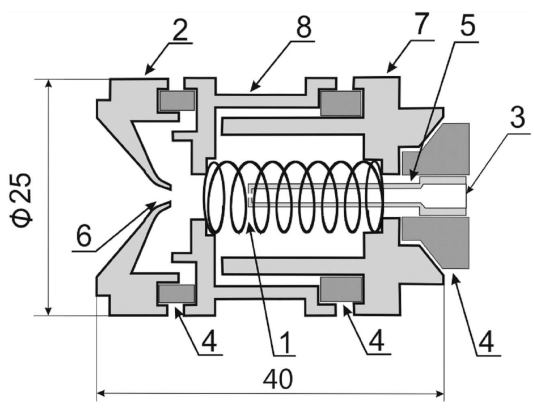

Fig. 1. Schematic view of the ion source: 1 - cathode filament, 2 - anode, 3 - gas inlet, 4 - insulators, 5 - evaporator, 6 - extraction opening, 7, 8 - hollow cathode cylinders.

after the ignition, the discharge is stable with the anode (discharge) voltage in the range 20-60 V. In many cases the anode voltage could be only slightly higher than the ionization potential of the ionized substance - in the case of indium an ion beam was observed even after the discharge was shut down, most probably due to the surface ionization on the hot cathode.

One of the most crucial parts of the ion source is an evaporator: a slim tube made of molybdenum, closed with a loose-fitted plug or a screw. A typical external diameter of the evaporator is $3 \mathrm{~mm}$, and its length is $\approx 30 \mathrm{~mm}$. The evaporator is filled with the feeding substance in the form of powder, small flakes or lumps. As previously mentioned, the evaporator is heated mainly by the hot spiral filament. A minor role is also played by arc discharge, due to the distance between the discharge region and the evaporator.

Vapors reach the discharge volume when they are ionized mostly during collisions with electrons having sufficient energy. Hence, the anode voltage should be at least two or three times larger than the ionization potential of the ionized substance.

The ionization chamber is placed inside an electromagnet. The additional magnetic field compensates the axial symmetry and the magnetic flux field density up to $14 \mathrm{mT}$ compensates the strong field from the spiral filament, and plays an important role in plasma confinement, forming the discharge plasma in order to achieve effective extraction of the produced ions. The ion beam is pulled out of the source through the extraction opening (diameter of $1 \mathrm{~mm}$ ). The beam is formed and accelerated by a conventional triple lens system. The primary beam reaches the electromagnetic separator and is divided into beamlets consisting of ions having the same charge/mass ratio.

\section{Characteristics of the ion source}

As in the case of the cylindrical anode ion source, characteristics for doubly charged ions were measured in order to find optimal working parameters for their production. The dependences of the ion current and anode voltage on the anode (discharge) current $I_{\mathrm{a}}$, cathode (filament) current $I_{\mathrm{c}}$ and magnetic field flux density $B$ were determined. Measurements were done for several solids (Al, Bi, Ge, As, In) and gases (Kr, Xe, He). The results are shown in Figs. 2 and 3.

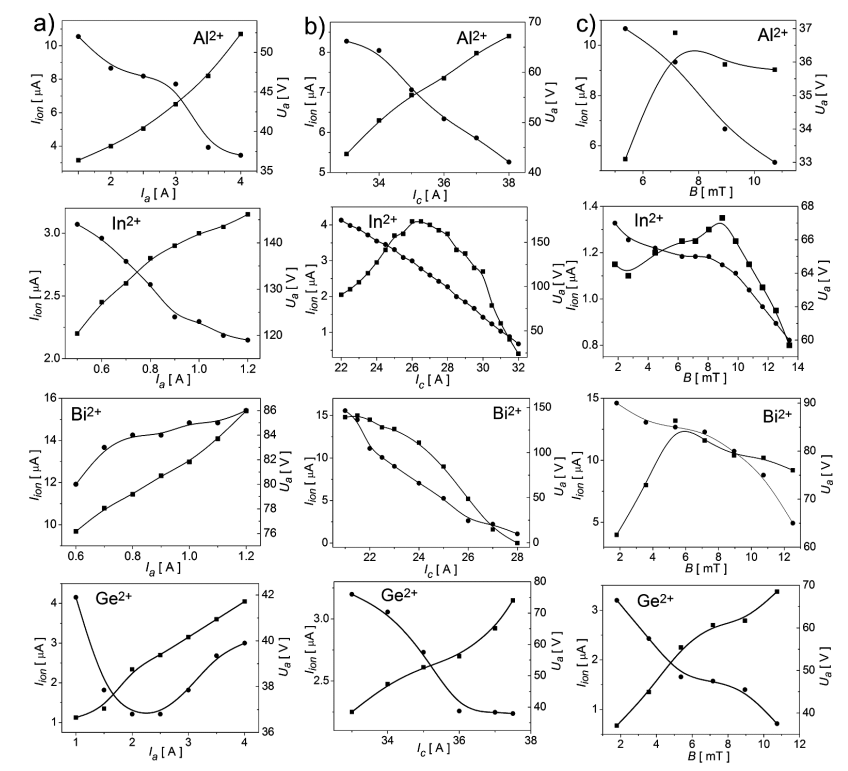

Fig. 2. Ion current (squares) and anode voltage (full circles) as the functions of discharge current (a), cathode current (b), and magnetic field flux density (c) for the doubly charged ions of the solids ( $\mathrm{Al}, \mathrm{In}, \mathrm{Bi}$ and $\mathrm{Ge}$ ).

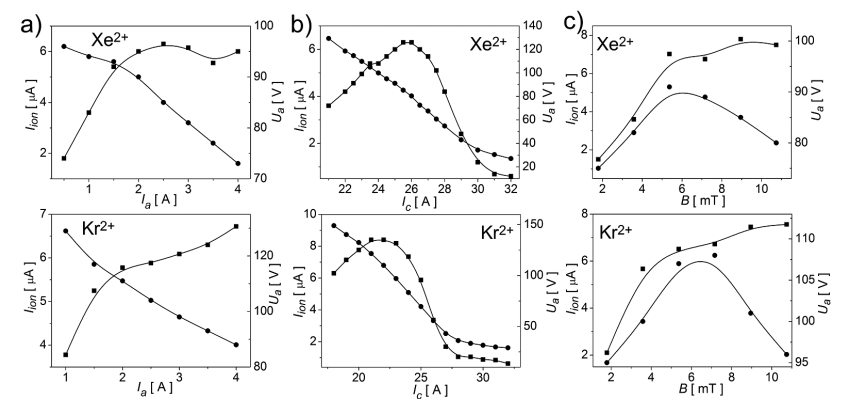

Fig. 3. The same as in Fig. 1 but for the inert gases (Xe and $\mathrm{Kr}$ ).

Analogously to the case of singly [18] and doubly [19] charged ions, one observes an increase of the ion current with the discharge current for all tested solids. This is due to the increasing temperature of the evaporator, which is partially heated by the discharge, leading to higher vapor pressure in the chamber. One should keep in mind that dependence of the anode voltage on $I_{\mathrm{a}}$ in the ion source with an evaporator is of much more complex nature than in the case of the arc discharge ion source with gaseous feeding. In the case of the gas-fed ion source, one observes the increase of $U_{\mathrm{a}}$ with $I_{\mathrm{a}}$ for a constant gas pressure in the chamber. In the case of 
the ion source with an evaporator, the pressure cannot be regarded as independent of $I_{\mathrm{a}}$, as mentioned above, and the plasma density increases with $I_{\mathrm{a}}$, leading to the reduction of $U_{\mathrm{a}}$.

Hence, one deals with two concurrent tendencies: the fall of $U_{\mathrm{a}}$ with the increasing $I_{\mathrm{a}}$ is seen for $\mathrm{Al}$ and $\mathrm{In}$, the opposite behavior is observed for $\mathrm{Bi}$, for which lower values of the cathode current are applied. Ge could be regarded as a mixed case, when both trends compete: one can see that the anode voltage decreases with $I_{\mathrm{a}}$ up to $I_{\mathrm{a}}=2 \mathrm{~A}$, then the plasma density rises and the second tendency prevails. One should keep in mind that production of doubly charged ions requires relatively high $U_{\mathrm{a}}(70-100 \mathrm{~V})$ - the decrease of discharge voltage results in lower energies of electrons and leads to less effective ionization. This could be especially well visible for the $U_{\mathrm{a}}\left(I_{\mathrm{c}}\right)$ and $I_{\mathrm{ion}}\left(I_{\mathrm{c}}\right)$ dependences measured for $\mathrm{In}$ and $\mathrm{Bi}$. Generally, this is a rule in the case of doubly charged ions production that $I_{\mathrm{c}}$ should be as low as possible. This is mostly due to the fact that the low thermal emission of electrons increases $U_{\mathrm{a}}$. Moreover, the evaporator is heated by a spiral filament, and high $I_{\mathrm{c}}$ leads to high vapor pressure and decreases $U_{\mathrm{a}}$. On the other hand, excessive reduction of $I_{\mathrm{c}}$ may lead to the shutdown of the discharge.

It is worth noticing that the shape of $I_{\text {ion }}\left(U_{\mathrm{a}}\right)$ dependences may resemble the shape of the electron impact ionization cross-section dependence on the electron energy, which could be seen for noble gases (see Fig. 3).

There are two kinds of $I_{\text {ion }}\left(U_{\mathrm{a}}\right)$ curves obtained for the described ion source. For In and $\mathrm{Bi}$, when relatively low values of $I_{\mathrm{a}}$ were applied $(\approx 1 \mathrm{~A})$ one can see a broad peak at 6-9 $\mathrm{mT}$, and a decrease of the $U_{\mathrm{a}}$ with $B$, as it was observed for cylindrical anode ion source [19]. In the cases when higher $I_{\mathrm{a}}$ were used (up to $4 \mathrm{~A}$ ) a stronger magnetic field that plays a role in forming plasma shape near the extraction opening, was preferred.

\section{Numerical model of doubly charged ion production}

The presented model of ionization describes the creation of singly and doubly charged ions based on the experimental cross-section data [20]. It is based on the assumption that the ionization process could be split [21] into $n_{\mathrm{s}}$ stages, when $n_{\mathrm{s}}$ is the ratio of the inner surface of the cavity and the surface of the extraction opening. For the sake of simplicity, a spherical cavity of the radius $R_{\text {ion }}=8 \mathrm{~mm}$ was considered. The radius of the extraction opening was $R_{\text {ext }}=0.5 \mathrm{~mm}$.

In every stage of ionization a neutral particle passes on average a distance $\lambda$ (of the order of the chamber diameter) and the probability of ionization to $q$-th charge state is

$$
P^{q}=1-\exp \left(-\frac{\lambda}{\lambda^{q}}\right),
$$

where $q$ is +1 or +2 , for the singly and doubly charged ions, respectively. Mean free path until ionization could be estimated as convolution of energy-dependent ionization cross-section and energy distribution of electrons, taking into account their drift velocity due to the $U_{\text {a volt- }}$ age. The mean free path $\lambda^{2+}$ is the order of magnitude larger than $\lambda^{+}$, but for large enough electron concentrations $\left(\approx 10^{21} \mathrm{~m}^{-3}\right)$ could be in the range of $100 \mathrm{~mm}$.

The extraction probabilities $P_{\mathrm{e}}^{q}$ for each kind of particles are proportional to the ratio of the extraction opening and the whole cavity surfaces. The number of particles in the $q$-th charge state could be then written as

$$
E_{i}^{q}=P_{i}^{q}\left(N_{i}^{q}+R_{i}^{q}\right),
$$

where $N_{i}^{q}=P^{q} N_{i}^{0}$ is the number of ions created in the $i$-th stage, $R_{i}^{q}$ is the number of ions that were not extracted up to the stage $i$. Relative currents for both types of ions are obtained by summing $N_{i}^{q}$ over all stages and dividing the results by the initial number of neutrals $N_{0}$.
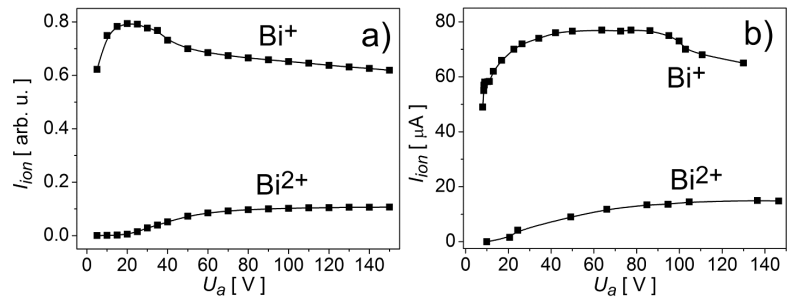

Fig. 4. Ion current of $\mathrm{Bi}^{2+}$ as the function of $U_{\mathrm{a}}$ : simulations (a) and experimental results (b).

The calculated $I_{\text {ion }}\left(U_{\mathrm{a}}\right)$ dependences are shown in Fig. 4a. The ion current of $\mathrm{Bi}^{2+}$ ions grows with $U_{\mathrm{a}}$ up to $\approx 80 \mathrm{~V}$ and then one observes a saturation. The shape of the curve resembles much the ionization cross-section data [20]. Figure $4 \mathrm{~b}$ shows the $I_{\text {ion }}\left(U_{\mathrm{a}}\right)$ curve measured in the experiment. One can see fair qualitative agreement of experimental and calculated data - also the ratio of the doubly and singly charged ions is similar in both cases. The fact that the spread of electron energy in the real ion source could be much larger than that predicted by the Maxwellian distribution may be the reason for different shapes of curves for $\mathrm{Bi}^{+}$ions.

\section{Conclusions}

Characteristics of the hollow cathode ion source with an evaporator were presented for the doubly charged ions of the solids (Al, $\mathrm{Bi}, \mathrm{Ge}, \mathrm{In})$ and also gases (Xe, $\mathrm{Kr}$ ). Optimal choice of the working parameters such as discharge and filament currents and external electromagnet current allows keeping sufficiently high anode voltage and a proper evaporator temperature resulting in currents of doubly charged ions in the range of $15 \mu \mathrm{A}\left(\mathrm{Bi}^{2+}\right), 10 \mu \mathrm{A}$ $\left(\mathrm{As}^{2+}, \mathrm{Al}^{2+}\right)$, and $5 \mu \mathrm{A}\left(\mathrm{In}^{2+}, \mathrm{Ge}^{2+}\right)$. The versatile construction of the ion source makes it suitable also for ion production using gases. For example the ion currents of $8 \mu \mathrm{A}$ and $5 \mu \mathrm{A}$ of $\mathrm{Xe}^{2+}$ and $\mathrm{Kr}^{2+}$, respectively, were obtained. Such ion yield enables moderate dose $\left(10^{15} \mathrm{~cm}^{-2}\right)$ implantations with energies up to $550 \mathrm{keV}$ within a single 
working cycle using UNIMAS-79 implanter at Institute of Physics in Lublin. A numerical model of the doubly and singly charged ion productions taking into account such factors as the geometry of the ion source chamber, plasma density, anode voltage etc. were presented. The calculated dependences of ion current on the anode voltage are in good agreement with the experimental data.

\section{Acknowledgments}

This work was supported by the Polish Ministry of Science and Higher Education, grant No. N N515 246637.

\section{References}

[1] G. Hayderer, S. Cernusca, M. Schmid, P. Varga, H.P. Winter, F. Aumayr, D. Niemann, V. Hoffmann, N. Stolterfoht, C. Lemell, L. Wirtz, J. Burgdörfer, Phys. Rev. Lett. 86, 3530 (2001).

[2] R. Ritter, G. Kowarik, W. Meissl, A.S. El-Said, A.S. Maunoury, A.S. Lebius, C. Dufour, M. Toulemonde, F. Aumayr, Vacuum 84, 1062 (2010).

[3] A.S. El-Said, R. Heller, W. Meissl, R. Ritter, S. Facsko, C. Lemell, B. Solleder, I.C. Gebeshuber, G. Betz, M. Toulemonde, W. Möller, J. Burgdörfer, F. Aumayr, Phys. Rev. Lett. 100, 237601 (2008).

[4] A.D. Pogrebnjak, O.G. Bakharev, V.A. Martynenko, V.A. Rudenko, R. Brusa, A. Zecca, R. Oechsner, H. Ryssel, I.A. Tikhomirov, A.I. Ryabchikov, Nucl. Instrum. Methods Phys. Res. B 94, 81 (1994).

[5] V.N. Popok, I.I. Azarko, R.I. Khaibullin, Techn. Phys. 47, 459 (2002).

[6] G. Rodrigues, P.S. Lakshmy, S. Kumar, A. Mandal, D. Kanjilal, R. Baskaran, A. Roy, Rev. Sci. Instrum. 81, 02B713 (2010).

[7] I. Draganic, T. Nedeljkovic, J. Jovovic, M. Šiljegovic, A. Dobrosavljevic, J. Phys.: Conf. Ser. 58, 427 (2007).
[8] G. Zschornack, F. Grossmann, V.P. Ovsyannikov, R. Heller, U. Kentsch, M. Kreller, M. Schmidt, A. Schwan, A. Silze, F. Ullmann, Mat.-wiss. Werkstofftech. 40, 285 (2009).

[9] V.N. Nevolin, V.Yu. Fominski, A.G. Gnedovets, G.A. Kiselev, Techn. Phys. 52, 1475 (2007).

[10] S. Gammino, L. Torrisi, G. Ciavola, L. Andò, J. Wolowski, L. Laska, J. Krasa, A. Picciotto, Nucl. Instrum. Methods Phys. Res. B 209, 345 (2003).

[11] L. Bischoff, G.L.R. Mair, C.J. Aidinis, C.A. Londos, C. Akhmadaliev, Th. Ganetsos, Ultramicroscopy 100, 1 (2004).

[12] A.S. Bugaev, V.I. Gushenets, G.Y. Yushkov, E.M. Oks, A. Anders, I. Brown, A. Gershkovich, P. Spadke, Russ. Phys. J. 44, 912 (2001).

[13] I.G. Brown, B. Feinberg, J.E. Galvin, J. Appl. Phys 63, 4889 (1988).

[14] M. Turek, A. Droździel, K. Pyszniak, S. Prucnal, Nucl. Instrum. Methods Phys. Res. A 654, 57 (2011).

[15] M. Turek, A. Droździel, K. Pyszniak, S. Prucnal, D. Mączka, Acta Phys. Pol. A 120, 184 (2011).

[16] The Physics and Technology of Ion Sources, Ed. I.G. Brown, Wiley-VCH, Berlin 2004.

[17] M. Turek, S. Prucnal, A. Drozdziel, K. Pyszniak, Rev. Sci. Instrum. 80, 043304 (2009).

[18] M. Turek, S. Prucnal, A. Drozdziel, K. Pyszniak, Nucl. Instrum. Methods Phys. Res. B 269, 700 (2011).

[19] M. Turek, A. Drozdziel, K. Pyszniak, D. Mączka, Przegląd Elektrotechniczny 88, 328 (2012) (in Polish).

[20] R.S. Freund, R.C. Wetzel, R.J. Shul, T.R. Hayes, Phys. Rev. A 41, 3575 (1990).

[21] A. Latuszyński, K. Pyszniak, A. Droździel, M. Turek, D. Mączka, J. Meldizon, Vacuum 81, 1150 (2007). 